\title{
Telomere Length Calibration from qPCR Measurement: Limitations of Current Method
}

\author{
Youjin Wang ${ }^{1}$, Sharon A. Savage ${ }^{1}$, Rotana Alsaggaf ${ }^{1}$, Geraldine Aubert ${ }^{2,3}$, \\ Casey L. Dagnall ${ }^{4,5}{ }^{\circledR}$, Stephen R. Spellman ${ }^{6}$, Stephanie J. Lee ${ }^{7,8}$, Belynda Hicks ${ }^{4,5}{ }^{\circ}$,
} Kristine Jones ${ }^{4,5}$, Hormuzd A. Katki ${ }^{9}$ and Shahinaz M. Gadalla ${ }^{1, *}$

1 Clinical Genetics Branch, Division of Cancer Epidemiology and Genetics, National Cancer Institute, National Institutes of Health, Bethesda, MD 20892, USA; youjin.wang@nih.gov (Y.W.); savagesh@mail.nih.gov (S.A.S.); rotana.alsaggaf@nih.gov (R.A.)

2 Terry Fox Laboratory, British Columbia Cancer Agency, Vancouver, BC V5Z 1L3, Canada; gaubert@bccrc.ca

Repeat Diagnostics Inc., North Vancouver, BC V7M 1A5, Canada

4 Cancer Genomics Research Laboratory, Division of Cancer Epidemiology and Genetics, National Cancer Institute, National Institutes of Health, Bethesda, MD 20892, USA; dagnallc@mail.nih.gov (C.L.D.); hicksbel@mail.nih.gov (B.H.); kristine.jones@nih.gov (K.J.)

5 Leidos Biomedical Research, Inc., Frederick National Laboratory for Cancer Research, Frederick, MD 21701, USA

6 Center for International Blood and Marrow Transplant Research, Minneapolis, MN 55401, USA; sspellma@nmdp.org

7 Center for International Blood and Marrow Transplant Research, Medical College of Wisconsin, Milwaukee, WI 53226, USA; sjlee@fredhutch.org

8 Clinical Research Division, Fred Hutchinson Cancer Research Center, Seattle, WA 98109, USA

9 Biostatistics Branch, Division of Cancer Epidemiology and Genetics, National Cancer Institute, National Institutes of Health, Bethesda, MD 20892, USA; katkih@mail.nih.gov

* Correspondence: shahinaz.gadalla@nih.gov; Tel.: +1-240-276-7254; Fax: +1-240-276-7836

Received: 29 August 2018; Accepted: 21 October 2018; Published: 24 October 2018

\begin{abstract}
Telomere length (TL) comparisons from different methods are challenging due to differences in laboratory techniques and data configuration. This study aimed to assess the validity of converting the quantitative polymerase chain reaction (qPCR) telomere/single copy gene (T/S) ratio to TL in kilobases $(\mathrm{kb})$. We developed a linear regression equation to predict TL from qPCR T/S using flow cytometry with fluorescence in situ hybridization (flow FISH) TL data from 181 healthy donors (age range $=19-53$ ) from the National Marrow Donor Program (NMDP) biorepository. TL measurements by qPCR and flow FISH were modestly correlated $\left(R^{2}=0.56, p<0.0001\right)$. In Bland-Altman analyses, individuals with the shortest ( $\leq 10$ th percentile) or longest ( $\geq 90$ th) flow FISH TL had an over- or under-estimated qPCR TL (bias $=0.89$ and $-0.77 \mathrm{~kb}$, respectively). Comparisons of calculated TL from the NMDP samples and 1810 age- and sex-matched individuals from the National Health and Nutrition Examination Survey showed significant differences (median $=7.1$ versus $5.8 \mathrm{~kb}$, respectively, $p<0.0001$ ). Differences in annual TL attrition were also noted (31 versus $13 \mathrm{bp} /$ year, respectively, $p=0.02$ ). Our results demonstrate that TL calculated in $\mathrm{kb}$ from $\mathrm{qPCR} \mathrm{T} / \mathrm{S}$ may yield biased estimates for individuals with the shortest or longest $\mathrm{TL}$, those often of high clinical interest. We also showed that calculated TL in $\mathrm{kb}$ from $\mathrm{qPCR}$ data are not comparable across populations and therefore are not necessarily useful.
\end{abstract}

Keywords: telomere length; qPCR; flow FISH; agreement 


\section{Introduction}

Telomeres consist of hexanucleotide (TTAGGG) repeats at the end of chromosomes capped by a protein complex [1]. Telomeres protect the end of the chromosomes from fusions and from being recognized as DNA breaks [2]. They shorten with each cell division, due to the incomplete replication of terminal DNA by conventional DNA polymerases [3]. Critically short telomeres can trigger genomic instability [4].

Inherited mutations in telomere-biology genes are recognized as the underlying biological mechanism in the telomere-biology disorders; dyskeratosis congenita (DC), and subsets of patients with severe aplastic anemia (SAA) or idiopathic pulmonary fibrosis (IPF) [5]. Such patients usually have a telomere length (TL) $<10$ th percentile-for-age by flow cytometry with fluorescence in situ hybridization (flow FISH) with DC patients having the shortest TL (<1st percentile-for-age) [6-8]. In the general population, TL has been linked to a number of age-related diseases such as cancer [9-11] and heart disease [12,13]. Recent studies also suggest a role for TL in optimal donor selection for hematopoietic cell transplantation (HCT) in patients with SAA [14-16].

Several TL measurement methods exist; the most commonly used are Southern blot, flow FISH, and quantitative polymerase chain reaction (qPCR). In Southern blots, TL is determined in kilobases $(\mathrm{kb})$ based on the terminal restriction fragment (TRF) length after DNA digestion with restriction endonucleases [17]. This method requires a large amount of DNA $(\sim 3 \mu \mathrm{g})$, which limits its applicability in many studies. In addition, TRF TL measurement includes the subtelomeric region, which may result in a TL overestimation. The flow FISH assay uses a telomere specific fluorescently labeled peptide nucleic acid (PNA) probe, and calculates the TL of distinct leukocyte subsets in kb based on the TRF calibration of a reference sample [18]. The qPCR technique of TL measurement estimates the relative ratio of the telomeric repeat amplified sequence to that of a single copy gene (T/S) [19]. It has emerged as a useful tool to measure TL in large epidemiology studies because of its high throughput capabilities and low DNA input requirement.

The absence of absolute quantification of TL with the qPCR assay prompted the use of conversion equations to determine the $\mathrm{kb}$ of TL in several studies [20-23]. Evaluating the validity of such an approach is particularly important in the context of its use in studies of clinical or public health impact. Here, we compared TL in $\mathrm{kb}$ from flow FISH data and that calculated using conversion equations from qPCR T/S measurements on the same samples. We also evaluated whether the use of such an approach can facilitate the comparability between results from different studies by comparing our data with available TL data from the National Health and Nutrition Examination Survey (NHANES).

\section{Materials and Methods}

\subsection{Study Participants}

We used TL measurements, by both qPCR and flow FISH assays, from 181 healthy donors, using data we generated in the context of studies evaluating the effect of donor TL on survival after hematopoietic stem cell transplantation $[15,16]$. Samples were provided by the National Marrow Donor Program $^{\circledR}$ (NMDP, Minneapolis, MN, USA)/Center for International Blood and Marrow Transplant Research $^{\circledR}$ (CIBMTR) (Minneapolis, MN, USA) biorepository. The median age of study participants was 36 years (range $=19-53$ ).

From the NHANES database (survey cycles 1999-2000 and 2001-2002) [24], we identified 1810 adults with qPCR TL data who were 1:10 frequency-matched to our study participants by age (in 5-year categories) and sex.

\subsection{Telomere Length Measurement}

For qPCR TL measurements, genomic DNA was extracted from peripheral blood mononuclear cells using a QIAamp DNA Blood Maxi Kit (QIAGEN, Inc., Germantown, MD, USA) for the NMDP cohort, and from whole blood using the Puregene (D-50 K) kit protocol (Gentra Systems, Inc., 
Minneapolis, MN, USA) for the NHANES samples [25]. Relative telomere length (RTL) was determined by a qPCR assay as described elsewhere [19]. Briefly, the method calculates the ratio of amplified telomere (T) signal to that of an autosomal single copy gene (S; 36B4 for NMDP samples, and human beta-globin for NHANES samples). The obtained value was then standardized using internal quality control (QC) samples. Method details for both cohorts are available elsewhere $[16,26]$.

For flow FISH TL measurement in the NMDP cohort, cryopreserved peripheral blood mononuclear cell samples (PBMCs) were washed and then mixed with bovine thymocytes of known telomere length as an internal control. Samples were next denatured with formamide at $87^{\circ} \mathrm{C}$ and hybridized with telomere-specific fluorescein labeled (CCCTAA) 3 PNA probes. The DNA was counterstained with LDS751 DNA dye. Lymphocytes were distinguished by flow cytometry based on LDS751 fluorescence intensity and light scatter signals. TL in total lymphocytes was analyzed in the present study. Method details are described elsewhere [18].

\subsection{Telomere Length Calculations in Kilobases}

From the NMDP cohort, we calculated the predicted TL by regressing the GPCR relative T/S ratio on the flow FISH total lymphocyte $\mathrm{TL}(\mathrm{kb})$ for the same individuals. The conversion equation is: $\mathrm{TL}=3.571+4.978 \times(\mathrm{T} / \mathrm{S})$.

The published conversion equation from NHANES was calculated based on the comparison of TRF from Southern blot analysis and T/S ratios using DNA samples from the human diploid fibroblast cell line IMR90 at different population doublings (https:/ / wwwn.cdc.gov/Nchs/Nhanes/2001-2002/ TELO_B.htm). The equation is: TL $(\mathrm{kb})=3.274+2.413 \times(\mathrm{T} / \mathrm{S})$.

\subsection{Statistical Analysis}

We used linear regression models and calculated the coefficient of determination $\left(R^{2}\right)$ to evaluate the strength of association between different measures of TL and between TL and age. Bland-Altman analysis was used to assess the agreement between $\mathrm{kb}$ of TL calculated from qPCR and that from flow FISH. The bias was estimated as the mean differences between calculated TL from qPCR and flow FISH TL. Limits of agreements (LoA), a range of acceptable differences, was defined as mean $\pm 1.96 \times$ standard deviation (SD) as recommended previously $[27,28]$. To examine whether agreement between calculated TL from qPCR and flow FISH TL was different in the TL extremes (that of greatest clinical interest), we repeated the analysis in the following strata of flow FISH TL:TL $\leq 10$ th percentile $(n=19)$, 10 th $<$ and $<90$ th percentile $(n=143)$, and $\geq 90$ th percentile $(n=19)$. The R package "blandr" was used for the Bland-Altman analysis [29].

To test whether the use of conversion equations is a valid tool for comparing results across studies, we used (1) Wilcoxon rank-sum test to compare the distribution of calculated TL (kb) in the NMDP cohort and in a sub-population from NHANES who were frequency-matched to the NMDP cohort by age and sex; and (2) linear regression models of TL on age to calculate the average annual TL attrition rate using cross-sectional data in the NMDP cohort from both the flow FISH TL and calculated TL in $\mathrm{kb}$ from $\mathrm{qPCR}$, and in the NHANES cohort from calculated TL using the NHANES published equation. We used unweighted methods for the analyses of NHANES data, while excluding one outlier with a calculated TL $>25 \mathrm{~kb}$ from the analysis.

All tests were two-sided with statistical significance defined as $p<0.05$. All statistical analyses were performed using SAS version 9.4 (SAS Institute Inc., Cary, NC, USA) and R software version 3.4.4 (R Foundation for Statistical Computing, Vienna, Austria). Correlation, distribution and regression plots were generated using R package "ggplot2" [30]. 


\section{Results}

\subsection{Flow FISH and qPCR TL in the NMDP Cohort}

One hundred and twelve (62\%) individuals were male, and median age at blood collection was 35 years for males (range $=20-53$ ), and 37 years for females (range $=19-52$ ). The median relative qPCR $\mathrm{TL}(\mathrm{T} / \mathrm{S}$ ratio) was 0.7 for both males (range $=0.33-1.38$ ) and females (range $=0.35-1.09$ ). The median flow FISH TL was $6.9 \mathrm{~kb}$ for males (range $=4.7-11.2$ ), and 7.2 for females (range = 3.7-9.5). TL was inversely correlated with age for both qPCR $(r=-0.30, p<0.0001$, Figure 1A) and flow FISH $(r=-0.33$, $p<0.0001$, Figure 1B).
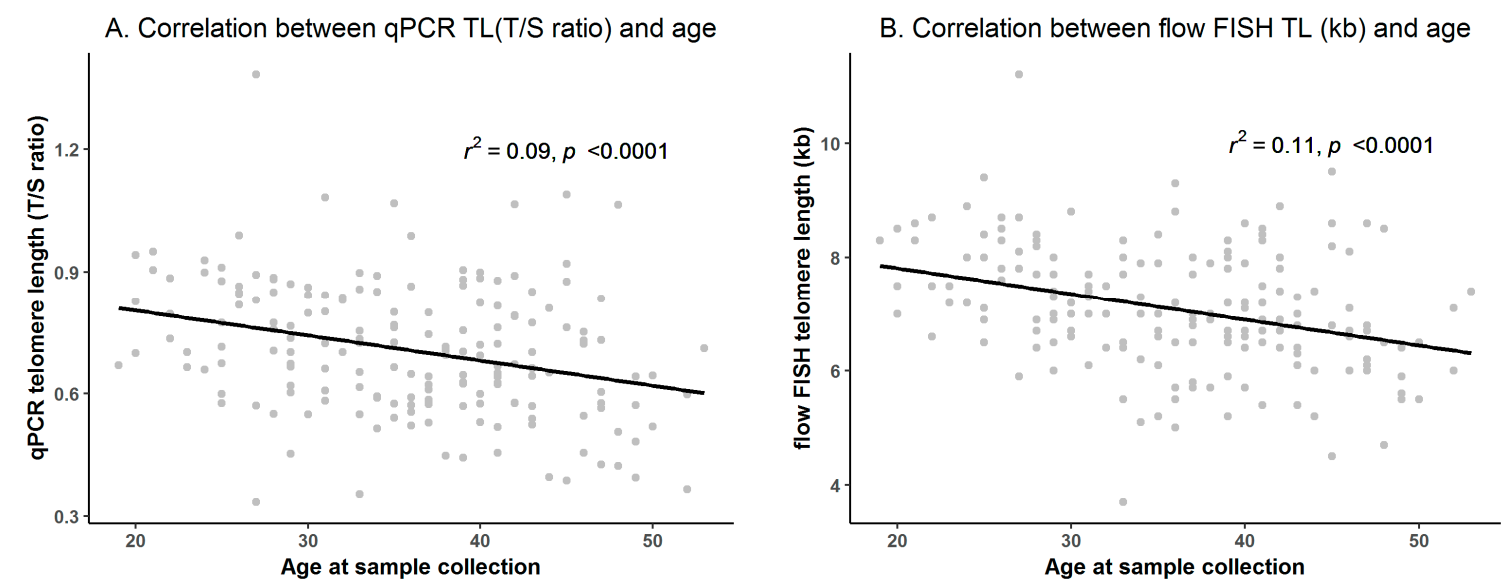

Figure 1. Correlation between telomere length (TL) and age (A) qPCR TL (T/S ratio); (B) Flow cytometry with fluorescence in situ hybridization (flow FISH) TL (kb).

\subsection{Comparability between Calculated $k b$ of qPCR and Flow FISH TL in the NMDP Cohort}

The correlation between calculated TL from qPCR and flow FISH TL was modest $\left(R^{2}=0.56\right.$, $p<0.0001$, Figure 2A). The median calculated TL was $7.1 \mathrm{~kb}$ (range $=5.2-10.5 \mathrm{~kb}$ ). In Bland-Altman analysis, the calculated TL showed an overall agreement with flow FISH data (bias $\pm \mathrm{SD}=0.00 \pm 0.72 \mathrm{~kb}$, LoA $=-1.40$ to $1.40 \mathrm{~kb}$, Figure $2 \mathrm{~B}$ ).

A.

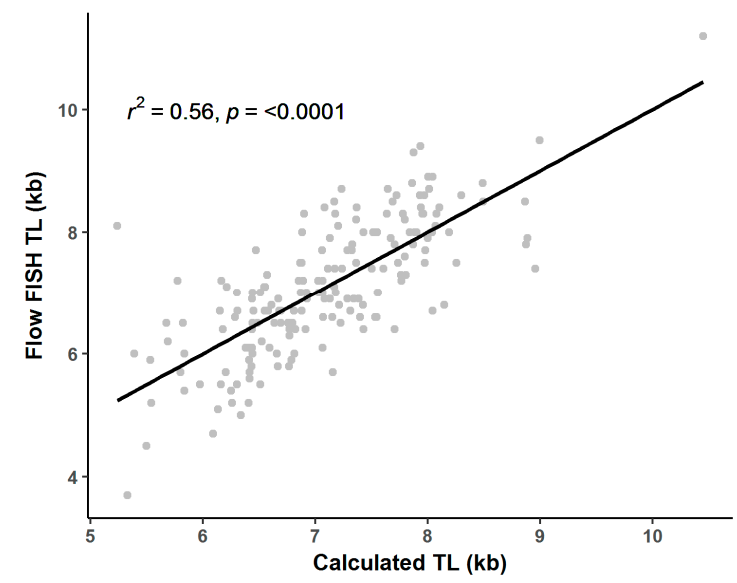

B.

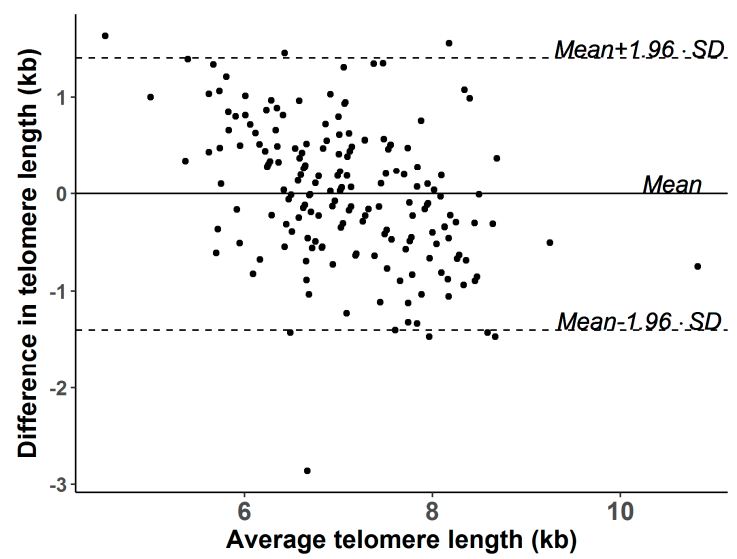

Figure 2. Correlation and agreement between calculated telomere length (TL) from conversion equation and flow cytometry with fluorescence in situ hybridization (flow FISH) TL in the National Marrow Donor Program ${ }^{\circledR}$ (NMDP) cohort. (A) Correlation between calculated qPCR TL (kb) and flow FISH TL; (B) Bland-Altman plot of agreement between calculated TL from conversion equation and flow FISH TL. 
In analysis stratified by flow FISH TL, acceptable agreement was only observed in individuals with a flow FISH TL within the normal range (between 10th and 90th percentiles (bias $=-0.02$ ), Figure 3A). The conversion equation resulted in TL over-estimation (bias $\pm \mathrm{SD}=0.89 \pm 0.41 \mathrm{~kb}$, Figure 3B) in individuals with short TL ( $\leq 10$ th percentile) and under-estimation (bias $\pm \mathrm{SD}=-0.77 \pm 0.49 \mathrm{~kb}$, Figure 3C) in individuals with long TL ( $\geq 90$ th percentile).

A. Flow FISH TL 5.8-8.4

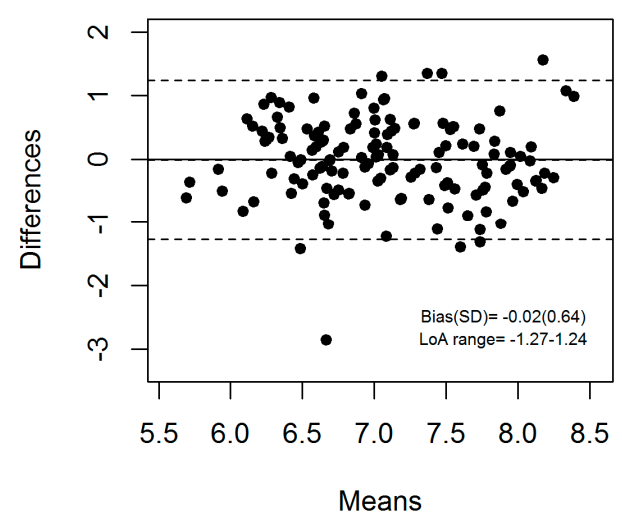

C. Flow FISH TL 8.5-11.2

\section{B. Flow FISH TL 3.7-5.7}

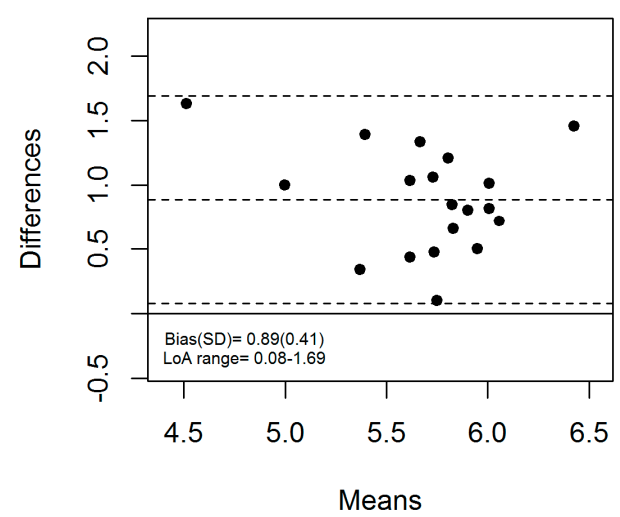

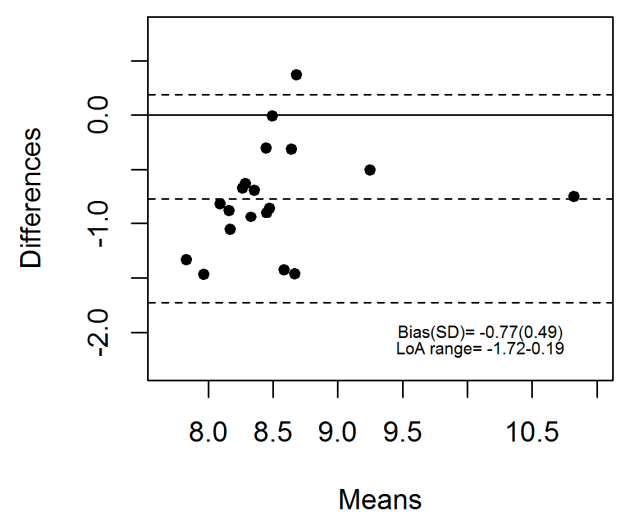

Figure 3. Flow cytometry with fluorescence in situ hybridization (Flow FISH) telomere length (TL) quintile stratified analysis of agreement between calculated TL from conversion equation and flow FISH TL in the National Marrow Donor Program ${ }^{\circledR}$ (NMDP) cohort. (A) Above 10th and below 90th percentile (TL 5.8-8.4); (B) Flow FISH TL $\leq$ 10th percentile (TL 3.7-5.7); (C) $\geq 90$ th percentile (TL 8.5-11.2).

\subsection{Comparison of Calculated TL between NMDP and NHANES Cohorts}

Using the NHANES published conversion equation, the median calculated TL in the age- and sex-matched NHANES cohort was $5.8 \mathrm{~kb}$ (range $=4.5-11.3 \mathrm{~kb}$ ). The median calculated TL in NHANES and our NMDP cohort was statistically significantly different (median calculated TL = 5.8 versus $7.1 \mathrm{~kb}$ for NHANES versus NMDP cohort, respectively; Wilcoxon rank-sum test $p<0.0001$ ). Figure 4 describes the distribution of the calculated TL in each cohort.

In the cross-sectional linear regression analyses of TL on age, we observed clear differences in the estimated annual average TL attrition between both cohorts. The flow FISH TL from the NMDP cohort showed an attrition rate of 46 base pairs (bp) per year of age (Figure 5A). Using the calculated kb TL from the same individuals, a lower attrition rate was noted (31 bp/year, Figure 5B); the difference was not statistically significant $(p=0.22)$. In the NHANES cohort, the use of their published conversion equation resulted in an annual attrition rate of $13 \mathrm{bp} /$ year (Figure 5C), which was significantly lower than that estimated from the calculated $\mathrm{kb}$ TL in the NMDP cohort $(p=0.02)$. 


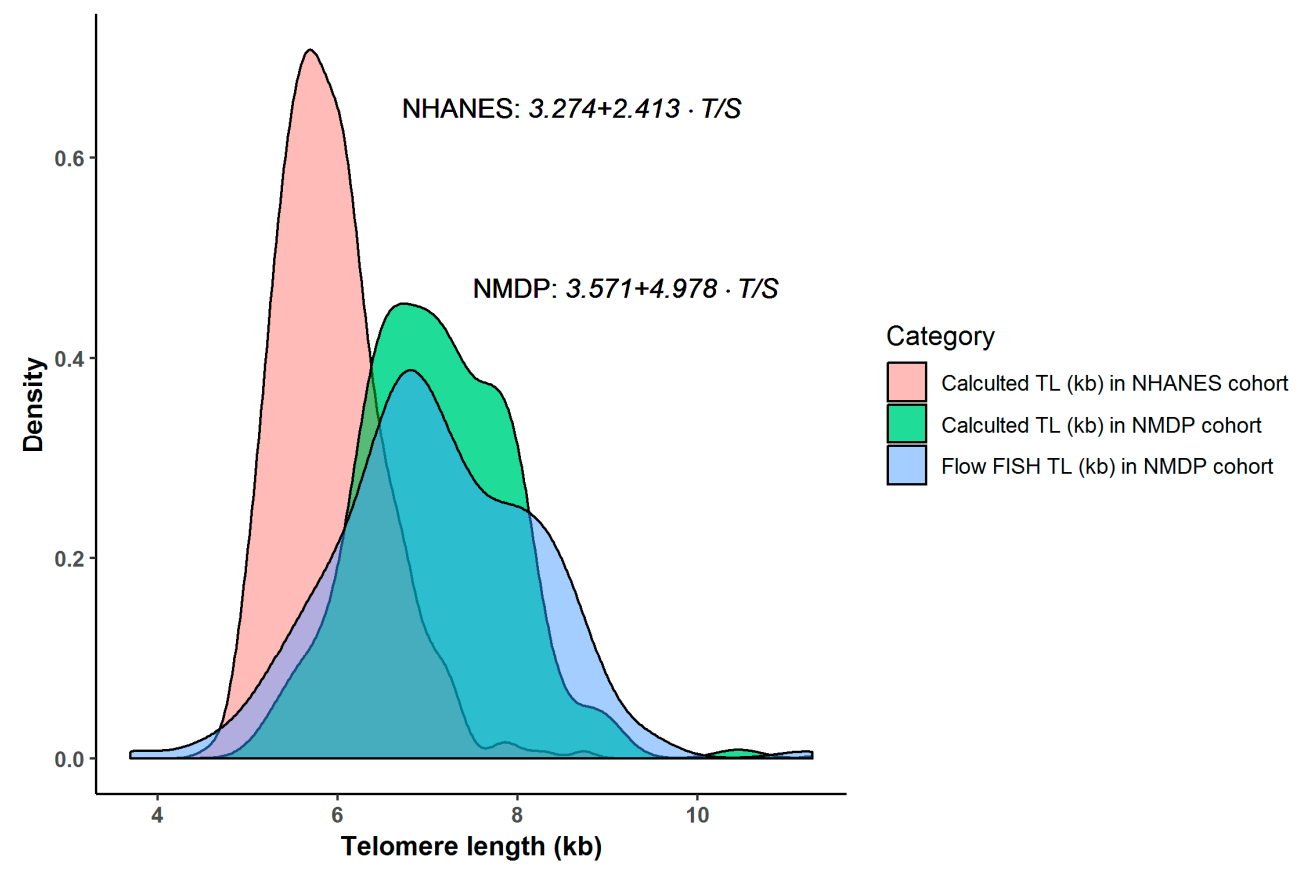

Figure 4. Distribution of calculated telomere length (TL) in the National Marrow Donor Program ${ }^{\circledR}$ (NMDP) and National Health and Nutrition Examination Survey (NHANES) cohorts.

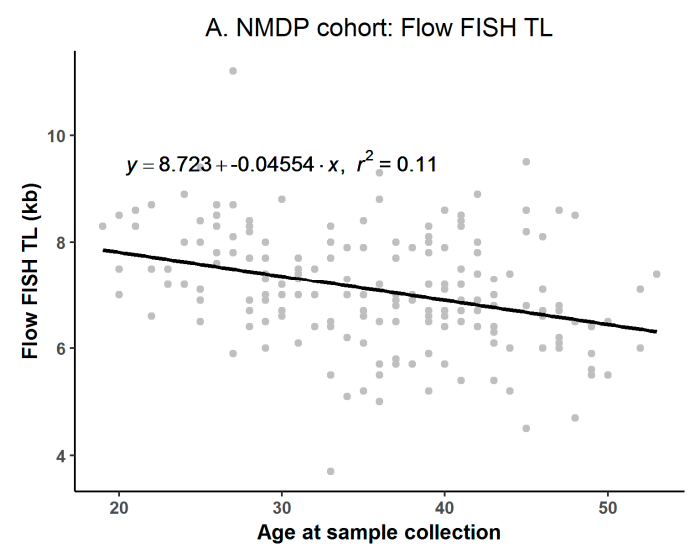

C. NHANES cohort: Calculated TL

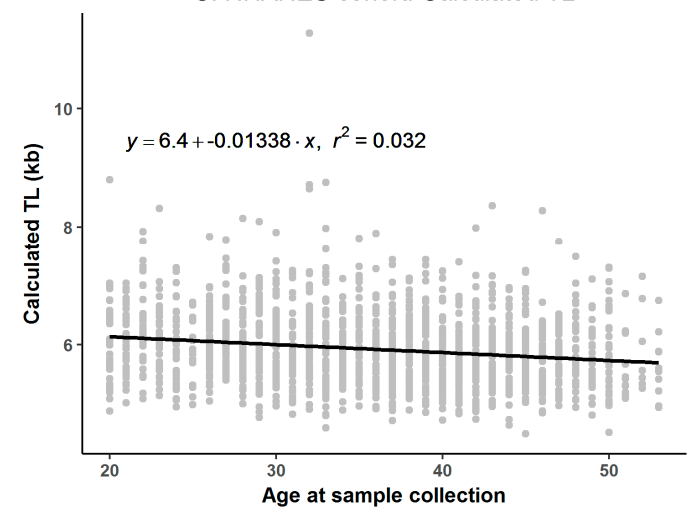

B. NMDP cohort: Calculated TL

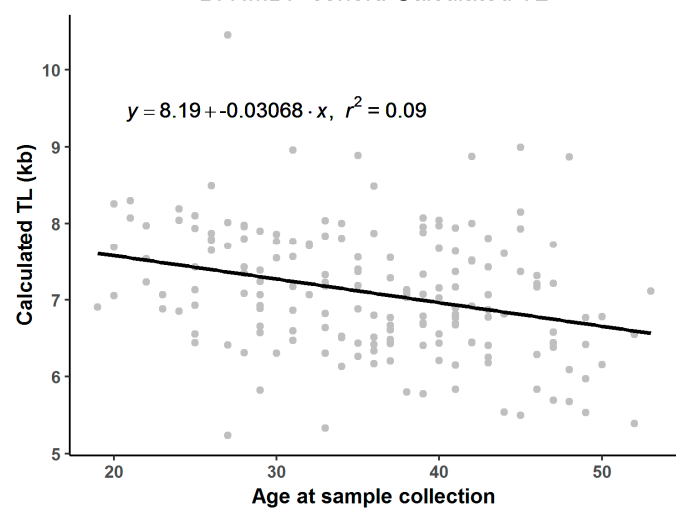

Figure 5. Annual telomere length (TL) attrition. (A) National Marrow Donor Program ${ }^{\circledR}$ (NMDP) cohort: flow cytometry with fluorescence in situ hybridization (flow FISH) TL; (B) NMDP cohort: calculated TL using conversion equation generated from the qPCR T/S ratio; (C) National Health and Nutrition Examination Survey (NHANES): calculated TL using the published conversion equation. 


\section{Discussion}

In this study, we showed that calculating the $\mathrm{kb}$ TL from the qPCR T/S ratio with current practice conversion equations (from linear regression models) results in imprecise estimates for individuals with short or long telomeres. Comparison of the calculated TL between our study population and ageand sex-matched individuals from the NHANES study showed that the equation for estimating the $\mathrm{kb}$ values of TL from the qPCR T/S ratio is only valid for the given data where the conversion equation is derived from, and cannot be used to compare TL results in different studies.

High throughput qPCR-based assays for TL measurement are being used extensively for a wide array of studies seeking to understand phenotype associations with TL. Our study and several others agree that the correlation between the qPCR TL measurement and that obtained from the highly accurate flow FISH assay is modest $\left(R^{2}=0.56\right.$ in our study, and $R^{2}=0.33$, and 0.42 in published studies) [31,32]. Similar results were observed when comparing QPCR TL with that obtained from the Southern blot assay $\left(R^{2}=0.35\right.$ and 0.43) [31,32]. Differences in the magnitude of correlation between studies may be related to the qPCR sensitivity to assay pre-analytic factors, such as DNA extraction, and inhibitor removal methods, well position, and sample storage conditions [33-36]. A previous study showed longer RTL in samples extracted with phenol/chloroform or PureGene kit, compared with the QIAamp method [34]. A subsequent study showed about $40 \%$ shorter RTL values with magnetic-particle methods, compared to salting-out extraction methods; the difference resulted in a stronger association between RTL and cardiovascular disease with salting-out DNA extraction [35].

Our data showed that qPCR results are less reliable for those with the shortest and longest TL. This is important, particularly in clinical studies where the TL association with disease is usually at the extremes. Our previous study evaluating the ability of qPCR TL to identify patients with DC (TL usually below the 1st percentile-for-age with flow FISH assay) showed that approximately $60 \%$ of patients were misclassified by qPCR TL (TL being above the 1st percentile-for-age) [37]. In agreement with our finding, a previous study showed a higher degree of bias in the calculated $\mathrm{kb}$ of TL from qPCR in patients with telomere-biology disorders (including DC) than that observed in healthy individuals (average bias in the comparison with flow FISH TL $=-1.15$ versus $-0.6 \mathrm{~kb}$, respectively) [31]. A more sophisticated modeling strategy in a large study, with enough individuals with extreme TL values, is needed to develop a robust conversion equation.

We observed substantial differences in the distribution of calculated TL in the NMDP cohort and that of the NHANES (median $=7.1$ versus 5.8 , and ranges $=5.2-10.5$ versus $4.5-11.3$, respectively), despite the similarity in age and sex distribution. This difference, at least in part, is related to the source of the conversion equation where we used the same samples for flow FISH analysis, while a fibroblast cell line was used for the TRF analysis in NHANES. This is also observed in large studies using cell line calibrators, where the median calculated TL ranged between 3.2 and $4.1 \mathrm{~kb}$ [20-22]; values much shorter than expected. A recent study using TRF identified a leukocyte TL of $5 \mathrm{~kb}$ as the point defining critically short TL; the study included more than 10,000 adults, almost none of those younger than age 60 had a TL $<5 \mathrm{~kb}$ [38].

In the current study, our flow FISH data showed a TL attrition rate of $46 \mathrm{bp} /$ year. This is similar to the rate observed in an independent cohort of more than 800 healthy individuals with flow FISH TL measured at the same laboratory (lymphocyte TL annual attrition rate in adults $=43 \mathrm{bp}$ ) [39], and a second cohort of 192 individuals measured in another laboratory [40]. Another study including 154 healthy individuals showed an annual TL attrition of $64 \mathrm{bp}$ for TRF and $50 \mathrm{bp}$ for flow FISH [41]. The observed difference in TL attrition rate from conversion equations in different cohorts of similar age and sex ( $31 \mathrm{bp} /$ year in the NMDP samples and $13 \mathrm{bp} /$ year in the NHANES population) argues against the usability of TL conversion equations in comparing results across studies.

Our study is limited by the unavailability of a direct absolute TL measurement (e.g., results from TRF) for comparison in the NMDP cohort. Instead, we used a flow FISH TL measurement that depends on TRF calibration via a reference sample. Yet, flow FISH is known for its accuracy and the strong correlation with TL measured by TRF [32,42]. This assures the validity of our results. 
In conclusion, our findings demonstrate that the use of linear equations for converting the qPCR T/S ratio to $\mathrm{kb}$ TL may introduce bias particularly at the bottom and top percentiles of TL. Caution should be exercised when comparing results from different studies using calculated TL from qPCR T/S ratio data since values are affected by the possible inter-laboratory variability in TL qPCR protocols and the underlying calibrator used.

Author Contributions: Study design: S.M.G. and S.A.S.; Telomere length measurement: G.A., C.L.D., B.H., K.J.; Statistical analysis: Y.W., R.A., S.M.G., H.A.K.; Data Interpretation: Y.W., S.A.S., H.A.K., S.M.G.; Sample availability: S.R.S., S.J.L.; Manuscript draft: Y.W., S.M.G.; Manuscript critical Review: All.

Funding: The study was supported by the Intramural Research Program of the Division of Cancer Epidemiology and Genetics, National Cancer Institute, National Institutes of Health. The CIBMTR is supported primarily by Public Health Service Grant/Cooperative Agreement 5U24CA076518 from the National Cancer Institute (NCI), the National Heart, Lung and Blood Institute (NHLBI) and the National Institute of Allergy and Infectious Diseases (NIAID); a Grant/Cooperative Agreement 4U10HL069294 from NHLBI and NCI; a contract HHSH250201200018C with Health Resources and Services Administration (HRSA/DHHS); and two Grants N00014-17-1-2388 and N0014-17-1-2850 from the Office of Naval Research.

Conflicts of Interest: G.A. is a part-time employee of Repeat Diagnostics Inc., a company specializing in clinical telomere length measurements. There are no other conflicts of interest to disclose.

\section{References}

1. O'Sullivan, R.J.; Karlseder, J. Telomeres: Protecting chromosomes against genome instability. Nat. Rev. Mol. Cell Biol. 2010, 11, 171-181. [CrossRef] [PubMed]

2. Aubert, G.; Lansdorp, P.M. Telomeres and aging. Physiol. Rev. 2008, 88, 557-579. [CrossRef] [PubMed]

3. Counter, C.M. The roles of telomeres and telomerase in cell life span. Mutat. Res./Rev. Genet. Toxicol. 1996, 366, 45-63. [CrossRef]

4. Feldser, D.M.; Hackett, J.A.; Greider, C.W. Telomere dysfunction and the initiation of genome instability. Nat. Rev. Cancer 2003, 3, 623-627. [CrossRef] [PubMed]

5. Savage, S.A.; Bertuch, A.A. The genetics and clinical manifestations of telomere biology disorders. Genet. Med. 2010, 12, 753-764. [CrossRef] [PubMed]

6. Armanios, M.Y.; Chen, J.J.; Cogan, J.D.; Alder, J.K.; Ingersoll, R.G.; Markin, C.; Lawson, W.E.; Xie, M.; Vulto, I.; Phillips, J.A., 3rd; et al. Telomerase mutations in families with idiopathic pulmonary fibrosis. N. Engl. J. Med. 2007, 356, 1317-1326. [CrossRef] [PubMed]

7. Alter, B.P.; Baerlocher, G.M.; Savage, S.A.; Chanock, S.J.; Weksler, B.B.; Willner, J.P.; Peters, J.A.; Giri, N.; Lansdorp, P.M. Very short telomere length by flow fluorescence in situ hybridization identifies patients with dyskeratosis congenita. Blood 2007, 110, 1439-1447. [CrossRef] [PubMed]

8. Alter, B.P.; Giri, N.; Savage, S.A.; Rosenberg, P.S. Telomere length in inherited bone marrow failure syndromes. Haematologica 2015, 100, 49-54. [CrossRef] [PubMed]

9. Willeit, P.; Willeit, J.; Mayr, A.; Weger, S.; Oberhollenzer, F.; Brandstatter, A.; Kronenberg, F.; Kiechl, S. Telomere length and risk of incident cancer and cancer mortality. JAMA 2010, 304, 69-75. [CrossRef] [PubMed]

10. Wentzensen, I.M.; Mirabello, L.; Pfeiffer, R.M.; Savage, S.A. The association of telomere length and cancer: A meta-analysis. Cancer Epidemiol. Biomark. Prev. 2011, 20, 1238-1250. [CrossRef] [PubMed]

11. Ma, H.; Zhou, Z.; Wei, S.; Liu, Z.; Pooley, K.A.; Dunning, A.M.; Svenson, U.; Roos, G.; Hosgood, H.D., 3rd; Shen, M.; et al. Shortened telomere length is associated with increased risk of cancer: A meta-analysis. PLoS ONE 2011, 6, e20466. [CrossRef] [PubMed]

12. Fitzpatrick, A.L.; Kronmal, R.A.; Gardner, J.P.; Psaty, B.M.; Jenny, N.S.; Tracy, R.P.; Walston, J.; Kimura, M.; Aviv, A. Leukocyte telomere length and cardiovascular disease in the cardiovascular health study. Am. J. Epidemiol. 2007, 165, 14-21. [CrossRef] [PubMed]

13. Haycock, P.C.; Heydon, E.E.; Kaptoge, S.; Butterworth, A.S.; Thompson, A.; Willeit, P. Leucocyte telomere length and risk of cardiovascular disease: Systematic review and meta-analysis. BMJ Br. Med. J. 2014, 349. [CrossRef] [PubMed]

14. Gadalla, S.M.; Wang, T.; Haagenson, M.; Spellman, S.R.; Lee, S.J.; Williams, K.M.; Wong, J.Y.; De Vivo, I.; Savage, S.A. Association between donor leukocyte telomere length and survival after unrelated allogeneic hematopoietic cell transplantation for severe aplastic anemia. JAMA 2015, 313, 594-602. [CrossRef] [PubMed] 
15. Gadalla, S.M.; Aubert, G.; Wang, T.; Haagenson, M.; Spellman, S.R.; Wang, L.; Katki, H.A.; Savage, S.A.; Lee, S.J. Donor telomere length and causes of death after unrelated hematopoietic cell transplantation in patients with marrow failure. Blood 2018, 131, 2393-2398. [CrossRef] [PubMed]

16. Gadalla, S.M.; Wang, T.; Dagnall, C.; Haagenson, M.; Spellman, S.R.; Hicks, B.; Jones, K.; Katki, H.A.; Lee, S.J.; Savage, S.A. Effect of recipient age and stem cell source on the association between donor telomere length and survival after allogeneic unrelated hematopoietic cell transplantation for severe aplastic anemia. Biol. Blood Marrow Transplant. 2016, 22, 2276-2282. [CrossRef] [PubMed]

17. Kimura, M.; Stone, R.C.; Hunt, S.C.; Skurnick, J.; Lu, X.; Cao, X.; Harley, C.B.; Aviv, A. Measurement of telomere length by the southern blot analysis of terminal restriction fragment lengths. Nat. Protoc. 2010, 5, 1596-1607. [CrossRef] [PubMed]

18. Baerlocher, G.M.; Vulto, I.; de Jong, G.; Lansdorp, P.M. Flow cytometry and fish to measure the average length of telomeres (flow fish). Nat. Protoc. 2006, 1, 2365-2376. [CrossRef] [PubMed]

19. Cawthon, R.M. Telomere measurement by quantitative pcr. Nucleic Acids Res. 2002, 30, e47. [CrossRef] [PubMed]

20. Weischer, M.; Nordestgaard, B.G.; Cawthon, R.M.; Freiberg, J.J.; Tybjærg-Hansen, A.; Bojesen, S.E. Short telomere length, cancer survival, and cancer risk in 47102 individuals. JNCI J. Natl. Cancer Inst. 2013, 105, 459-468. [CrossRef] [PubMed]

21. Weischer, M.; Bojesen, S.E.; Cawthon, R.M.; Freiberg, J.J.; Tybjærg-Hansen, A.; Nordestgaard, B.G. Short telomere length, myocardial infarction, ischemic heart disease, and early death. Arterioscler. Thromb. Vasc. Biol. 2012, 32, 822-829. [CrossRef] [PubMed]

22. Scheller Madrid, A.; Rode, L.; Nordestgaard, B.G.; Bojesen, S.E. Short telomere length and ischemic heart disease: Observational and genetic studies in 290,022 individuals. Clin. Chem. 2016, 62, 1140-1149. [CrossRef] [PubMed]

23. Townsley, D.M.; Dumitriu, B.; Liu, D.; Biancotto, A.; Weinstein, B.; Chen, C.; Hardy, N.; Mihalek, A.D.; Lingala, S.; Kim, Y.J.; et al. Danazol treatment for telomere diseases. N. Engl. J. Med. 2016, 374, 1922-1931. [CrossRef] [PubMed]

24. Needham, B.L.; Adler, N.; Gregorich, S.; Rehkopf, D.; Lin, J.; Blackburn, E.H.; Epel, E.S. Socioeconomic status, health behavior, and leukocyte telomere length in the national health and nutrition examination survey, 1999-2002. Soc. Sci. Med. (1982) 2013, 85, 1-8. [CrossRef] [PubMed]

25. Steinberg, K.; Beck, J.; Nickerson, D.; Garcia-Closas, M.; Gallagher, M.; Caggana, M.; Reid, Y.; Cosentino, M.; Ji, J.; Johnson, D.; et al. DNA banking for epidemiologic studies: A review of current practices. Epidemiology 2002, 13, 246-254. [CrossRef] [PubMed]

26. Lin, J.; Epel, E.; Cheon, J.; Kroenke, C.; Sinclair, E.; Bigos, M.; Wolkowitz, O.; Mellon, S.; Blackburn, E. Analyses and comparisons of telomerase activity and telomere length in human $\mathrm{t}$ and $\mathrm{b}$ cells: Insights for epidemiology of telomere maintenance. J. Immunol. Methods 2010, 352, 71-80. [CrossRef] [PubMed]

27. Bland, J.M.; Altman, D.G. Statistical methods for assessing agreement between two methods of clinical measurement. Lancet (Lond. Engl.) 1986, 1,307-310. [CrossRef]

28. Bland, J.M.; Altman, D.G. Comparing methods of measurement: Why plotting difference against standard method is misleading. Lancet (Lond. Engl.) 1995, 346, 1085-1087. [CrossRef]

29. Datta, D. Blandr: A Bland-Altman Method Comparison Package for R. Zenodo. DOI:10.5281/zenodo.824514 2017. Available online: https:/ / github.com/deepankardatta/blandr (accessed on 1 May 2018).

30. Wickham, H. Ggplot2: Elegant Graphics for Data Analysis; Springer-Verlag: New York, NY, USA, 2016.

31. Gutierrez-Rodrigues, F.; Santana-Lemos, B.A.; Scheucher, P.S.; Alves-Paiva, R.M.; Calado, R.T. Direct comparison of flow-fish and qpcr as diagnostic tests for telomere length measurement in humans. PLoS ONE 2014, 9, e113747. [CrossRef] [PubMed]

32. Khincha, P.P.; Dagnall, C.L.; Hicks, B.; Jones, K.; Aviv, A.; Kimura, M.; Katki, H.; Aubert, G.; Giri, N.; Alter, B.P.; et al. Correlation of leukocyte telomere length measurement methods in patients with dyskeratosis congenita and in their unaffected relatives. Int. J. Mol. Sci. 2017, 18, 1765. [CrossRef] [PubMed]

33. Eisenberg, D.T.; Kuzawa, C.W.; Hayes, M.G. Improving qpcr telomere length assays: Controlling for well position effects increases statistical power. Am. J. Hum. Biol. 2015, 27, 570-575. [CrossRef] [PubMed] 
34. Cunningham, J.M.; Johnson, R.A.; Litzelman, K.; Skinner, H.G.; Seo, S.; Engelman, C.D.; Vanderboom, R.J.; Kimmel, G.W.; Gangnon, R.E.; Riegert-Johnson, D.L.; et al. Telomere length varies by DNA extraction method: Implications for epidemiologic research. Cancer Epidemiol. Biomark. Prev. 2013, 22, 2047-2054. [CrossRef] [PubMed]

35. Raschenberger, J.; Lamina, C.; Haun, M.; Kollerits, B.; Coassin, S.; Boes, E.; Kedenko, L.; Köttgen, A.; Kronenberg, F. Influence of DNA extraction methods on relative telomere length measurements and its impact on epidemiological studies. Sci. Rep. 2016, 6, 25398. [CrossRef] [PubMed]

36. Dagnall, C.L.; Hicks, B.; Teshome, K.; Hutchinson, A.A.; Gadalla, S.M.; Khincha, P.P.; Yeager, M.; Savage, S.A. Effect of pre-analytic variables on the reproducibility of qpcr relative telomere length measurement. PLoS ONE 2017, 12, e0184098. [CrossRef] [PubMed]

37. Gadalla, S.M.; Khincha, P.P.; Katki, H.A.; Giri, N.; Wong, J.Y.Y.; Spellman, S.; Yanovski, J.A.; Han, J.C.; De Vivo, I.; Alter, B.P.; et al. The limitations of qpcr telomere length measurement in diagnosing dyskeratosis congenita. Mol. Genet. Genomic Med. 2016, 4, 475-479. [CrossRef] [PubMed]

38. Steenstrup, T.; Kark, J.D.; Verhulst, S.; Thinggaard, M.; Hjelmborg, J.V.B.; Dalgard, C.; Kyvik, K.O.; Christiansen, L.; Mangino, M.; Spector, T.D.; et al. Telomeres and the natural lifespan limit in humans. Aging (Albany N. Y.) 2017, 9, 1130-1142. [CrossRef] [PubMed]

39. Aubert, G.; Baerlocher, G.M.; Vulto, I.; Poon, S.S.; Lansdorp, P.M. Collapse of telomere homeostasis in hematopoietic cells caused by heterozygous mutations in telomerase genes. PLoS Genet. 2012, 8, e1002696. [CrossRef] [PubMed]

40. Alder, J.K.; Hanumanthu, V.S.; Strong, M.A.; DeZern, A.E.; Stanley, S.E.; Takemoto, C.M.; Danilova, L.; Applegate, C.D.; Bolton, S.G.; Mohr, D.W.; et al. Diagnostic utility of telomere length testing in a hospital-based setting. Proc. Natl. Acad. Sci. USA 2018. [CrossRef] [PubMed]

41. Behrens, Y.L.; Thomay, K.; Hagedorn, M.; Ebersold, J.; Henrich, L.; Nustede, R.; Schlegelberger, B.; Göhring, G. Comparison of different methods for telomere length measurement in whole blood and blood cell subsets: Recommendations for telomere length measurement in hematological diseases. Genes Chromosomes Cancer 2017, 56, 700-708. [CrossRef] [PubMed]

42. Aubert, G.; Hills, M.; Lansdorp, P.M. Telomere length measurement-caveats and a critical assessment of the available technologies and tools. Mutat. Res. 2012, 730, 59-67. [CrossRef] [PubMed] 